Article

\title{
Immediate and Delayed Meteorological Effects on COVID-19 Time-Varying Infectiousness in Tropical Cities
}

\author{
Xerxes Seposo $^{1, *(\mathbb{D})}$, Chris Fook Sheng $\mathrm{Ng}^{1}(\mathbb{D})$ and Lina Madaniyazi ${ }^{1,2}$ \\ 1 School of Tropical Medicine and Global Health, Nagasaki University, Nagasaki 852-8521, Japan; \\ chrisng@nagasaki-u.ac.jp (C.F.S.N.); lina.madaniyazi@nagasaki-u.ac.jp (L.M.) \\ 2 Department of Pediatric Infectious Diseases, Institute of Tropical Medicine, Nagasaki University, \\ Nagasaki 852-8521, Japan \\ * Correspondence: seposo.xerxestesoro@nagasaki-u.ac.jp
}

Citation: Seposo, X.; Ng, C.F.S.; Madaniyazi, L. Immediate and Delayed Meteorological Effects on COVID-19 Time-Varying Infectiousness in Tropical Cities. Atmosphere 2021, 12, 513. https:// doi.org/10.3390/atmos12040513

Academic Editor:

Andreas Matzarakis

Received: 23 March 2021

Accepted: 15 April 2021

Published: 18 April 2021

Publisher's Note: MDPI stays neutral with regard to jurisdictional claims in published maps and institutional affiliations.

Copyright: (c) 2021 by the authors Licensee MDPI, Basel, Switzerland. This article is an open access article distributed under the terms and conditions of the Creative Commons Attribution (CC BY) license (https:/ / creativecommons.org/licenses/by/ $4.0 /)$.

\begin{abstract}
The novel coronavirus, which was first reported in Wuhan, China in December 2019, has been spreading globally at an unprecedented rate, leading to the virus being declared a global pandemic by the WHO on 12 March 2020. The clinical disease, COVID-19, associated with the pandemic is caused by the pathogen severe acute respiratory syndrome coronavirus 2 (SARS-CoV-2). Aside from the inherent transmission dynamics, environmental factors were found to be associated with COVID-19. However, most of the evidence documenting the association was from temperate locations. In this study, we examined the association between meteorological factors and the timevarying infectiousness of COVID-19 in the Philippines. We obtained the daily time series from 3 April 2020 to 2 September 2020 of COVID-19 confirmed cases from three major cities in the Philippines, namely Manila, Quezon, and Cebu. Same period city-specific daily average temperature (degrees Celsius; ${ }^{\circ} \mathrm{C}$ ), dew point (degrees Celsius; ${ }^{\circ} \mathrm{C}$ ), relative humidity (percent; \%), air pressure (kilopascal; $\mathrm{kPa}$ ), windspeed (meters per second; $\mathrm{m} / \mathrm{s}$ ) and visibility (kilometer; $\mathrm{km}$ ) data were obtained from the National Oceanic and Atmospheric Administration-National Climatic Data Center. City-specific COVID-19-related detection and intervention measures such as reverse transcriptase polymerase chain reaction (RT-PCR) testing and community quarantine measures were extracted from online public resources. We estimated the time-varying reproduction number $\left(R_{t}\right)$ using the serial interval information sourced from the literature. The estimated $R_{t}$ was used as an outcome variable for model fitting via a generalized additive model, while adjusting for relevant covariates. Results indicated that a same-day and the prior week's air pressure was positively associated with an increase in $\mathrm{R}_{\mathrm{t}}$ by 2.59 (95\% CI: 1.25 to 3.94) and 2.26 (95\% CI: 1.02 to 3.50), respectively. Same-day RT-PCR was associated with an increase in Rt, while the imposition of community quarantine measures resulted in a decrease in $\mathrm{R}_{\mathrm{t}}$. Our findings suggest that air pressure plays a role in the infectiousness of COVID19. The determination of the association of air pressure on infectiousness, aside from the testing frequency and community quarantine measures, may aide the current health systems in controlling the COVID-19 infectiousness by integrating such information into an early warning platform.
\end{abstract}

Keywords: time-varying reproduction number; air pressure; community quarantine; tropical; COVID-19; RT-PCR

\section{Introduction}

The novel coronavirus, which was first reported in Wuhan, China in December 2019 [1], has been spreading globally in an unprecedented rate, leading to the virus being declared as a global pandemic by the World Health Organization (WHO) [2] on 12 March 2020. The clinical disease, COVID-19, associated with the pandemic is caused by the pathogen severe acute respiratory syndrome coronavirus 2 (SARS-CoV-2) [1]. Clinical symptoms associated with the infection included fever, fatigue and dry cough, among others [3], and is transmitted through droplets [4]. Countries across the globe have been battling 
the pandemic and struggling to keep it under control by imposing stringent control measures [5]. In Southeast Asia (SEA), several countries have imposed community quarantine (CQ) measures to combat the pandemic [6]. However, amidst such implementation, the pandemic is yet to be controlled in several SEA countries.

Among the SEA countries, the Philippines, with a population of more than 108 million, ranks second in the region with regard to the total number of infected cases, which is at 892,880 as of the 14 April 2021 [6]. The COVID-19 timeline in the Philippines started on 30 January 2020, when a 38-year-old female Chinese national was recorded as the first COVID19 case in the country. A month after the first recorded case on March 7, the Department of Health (DOH) recorded the first local transmission to a 62-year-old female [7]. A day after, on March 8, the national government declared the pandemic a state of national public health emergency [8] and subsequently imposed an enhanced community quarantine (ECQ) measure on 15 March 2020 [9] to curb the progression of the pandemic. The country has since imposed variants of CQ levels subject to the progression of the pandemic in the local areas [10]. The highest CQ level, enhanced CQ, entailed stringent limitations on movement and population. The restrictions were further relaxed as the CQ levels decrease towards the least stringent modified general $C Q$, which is a transitional phase between a general CQ towards the new normal lifestyle [11].

The transmission dynamics of COVID-19 infection [12-15] may be linked to the variations in the incident cases and the eventual infectiousness of the disease in the country. Aside from these transmission dynamics, environmental factors (i.e., weather, air pollution levels) were observed to be linked with COVID-19 incidence [16-18]. Bashir et al. [19] observed a significant correlation of average temperature, minimum temperature, and air quality with the COVID-19 in New York. Similar findings were observed by Tosepu et al. [20] in Jakarta, Indonesia, whereby average temperature was significantly correlated with the infection. In a recent review paper [21], temperature was noted to affect COVID-19 incidence. The authors particularly noted that COVID-19 incidence increased as temperature decreased, with the highest COVID-19 incidence at $0-17^{\circ} \mathrm{C}$. Bukhari et al. [22] share a similar finding, whereby they estimated that 3 million reported cases have occurred in regions with temperatures between $3^{\circ} \mathrm{C}$ and $17^{\circ} \mathrm{C}$. In Japan, lower COVID-19 morbidity and mortality rates were observed for higher temperature periods [23]. Relative humidity also exhibited inconsistent yet significant associations with COVID-19 incidence among temperate countries in Asia $[16,24]$. On the contrary, meteorological variables such as air pressure and visibility have been documented to affect the incidence of infectious diseases such as avian influenza [25] and Middle East respiratory syndrome (MERS) [26].

While incidence and mortality data provide insights in the possible association, these metrics reflect only a portion of the transmission dynamics. A candidate metric for the time series modeling, while considering the infectiousness, is a time-varying reproduction number $\left(R_{t}\right)$. In brief, $R_{t}$ is the ratio of the number of new infections generated at time step $t$, represented by $I_{t}$, to the total infectiousness of the infected individuals at time $t$, given by $\sum_{s=1}^{t} I_{t-s} W_{s}$, the sum of infection incidence up to time step $t \neq 1$, weighted by the infectivity function $w_{s}$ [27]. For a more detailed explanation of $R_{t}$, we encourage the readers to refer to the works of Cori et al. [27]. $R_{t}$ has been shown to provide information of how the transmission intensity of the epidemic changes temporally, while accounting for the relevant transmission dynamics of the infection.

Amidst the increasing number of studies which examined the effect of meteorological variables on COVID-19 [17,20,28-33], a majority of these studies mostly focused on correlations, with a few studies examining possible causal associations. Aside from the nature of risk estimation, the unique atmospheric dynamics in tropical countries, which sets it apart from temperate locations, present an opportunity to examine the impact of meteorological factors on COVID-19. The Philippines, an archipelagic country, located near the equator experiences two seasons: dry and wet, with annual average temperature of $28{ }^{\circ} \mathrm{C}$ and an annual average relative humidity hovering between 70 and $80 \%[34,35]$. The unique tropical characteristic of the Philippines provides an avenue examining the 
progression of the pandemic. Likewise, there is little or no emphasis on the delayed effect of meteorological factors on COVID-19, apart from what has been mostly examined with unlagged exposure variables in most studies which heavily utilized COVID-19 incidence instead of infectiousness. In this study, we examined the association of meteorological variables and the time-varying infectiousness of COVID-19 in the Philippines.

\section{Materials and Methods}

\subsection{COVID-19-Related Data}

We obtained the daily time series from 3 April 2020 to 2 September 2020 of COVID-19 confirmed cases $(n=61,908)$ from three major cities in the Philippines, namely Manila, Quezon, and Cebu, through the DOH COVID-19 case tracker data portal [7]. We restricted the analysis to September 2020, due to the downsizing of testing capacity by several major institutions. The selection of the cities was based primarily on the magnitude of the cumulative COVID-19 cases, at the time of data collection, and the existence of a meteorological station, as shown in Table S1. We also included the location-specific population and cumulative COVID-19 incidence (per 1000 population). The locations were sorted based on a descending order wherein Manila city recorded most cases. There are cities, such as Makati, whereby the COVID-19 cumulative incidence is higher than other locations; however, due to the lack of a monitoring station, we did not include these in the study.

We also included detection and intervention-related covariates of testing capacity [36] and community quarantines [37], as additional covariates which have been observed to affect COVID-19 infectiousness. We extracted the daily reverse transcription polymerase chain reaction (RT-PCR) tests from the DOH COVID-19 case tracker data portal [7]. A detailed description of the extraction and management protocol is documented in the Supplementary Materials. While COVID-19 incidence was recorded as early as March 2020, since RT-PCR tests were only available from 3 April 2020, we decided to shorten the study period to match the RT-PCR test data to be coherent in the subsequent analyses.

CQ measures vary between cities subject to the status of local transmission, thus the importance of extracting city-specific CQ implementation timeframes (depicted in Figure S1) of well-defined "start" and "end" dates from the publicly available resolutions approved and endorsed by the IATF [11]. In brief, the first level $(C Q=1)$ represents the modified general community quarantine (MGCQ), the second level $(C Q=2)$ general community quarantine $(\mathrm{GCQ})$, the third level $(\mathrm{CQ}=3)$ modified enhanced community quarantine $(M E C Q)$ and the most stringent $(C Q=4)$ enhanced community quarantine (ECQ); specifications of each CQ classification are further elaborated in Table S2.

\subsection{Meteorological Data}

Same period city-specific daily average temperature (degrees Celsius; ${ }^{\circ} \mathrm{C}$ ), dew point (degrees Celsius; ${ }^{\circ} \mathrm{C}$ ), relative humidity (percent; \%), air pressure (kilopascal; $\mathrm{kPa}$ ), windspeed (meter per second; $\mathrm{m} / \mathrm{s}$ ) and visibility (kilometer; $\mathrm{km}$ ) data were obtained from the National Oceanic and Atmospheric Administration-National Climatic Data Center; NOAA-NCDC [38]. Locations of the monitoring stations per city are shown in Figure S2.

\subsection{Time-Varying $R_{t}$ Estimation}

$R_{t}$, in principle, is a function of time-dependent factors, which include but are not limited to the transmission probability, contact rate specific to the population and susceptible population, among others [39]. We utilized the COVID-19 serial interval (SI) information from Li et al. [12] with the mean SI of 7.5 days and a standard deviation of 3.4 days. The selected parameters were then used to populate the function provided by the EpiEstim package [40] in R Statistical programming [41] software to calculate the city-specific $R_{t}$ (shown in Figure S3, right panels). 


\subsection{Statistical Analyses}

We utilized a Generalized Additive Model (GAM) in examining the association of $R_{t}$ and the relevant exposure variables. In this case, $R_{t}$ was assumed to follow a Gaussian distribution. We separately examined the same-day (unlagged) and lagged association of the exposure variables and $R_{t}$, alongside the adjustment for the temporal controls of time and day of the week (dow). The "base model" only included the temporal controls. Hereafter, both same-day and lagged exposure variables were adjusted for the covariates of time and dow. We modelled the association of the lagged exposure variables and $\mathrm{R}_{\mathrm{t}} \mathrm{using}$ single lag models with a lag extending to 14 days, as shown in Figures 2 and S3. We set the maximum lag for 14 days considering the 14-day incubation period of COVID-19 [42,43]. Same-day and lagged covariates which exhibited statistical significance were included in the initial full model, for stepwise regression. The initial full model included air pressure Lags 0 to 8, RT-PCR test Lags 0 to 7, and the interaction term for CQ and time. The backward elimination process posits that the least significant covariates will be dropped one-by-one until arriving at the final model [44]. Stepwise regression via backward elimination favored air pressure (Lag 0 and Lag 7), RT-PCR test (Lag 0 ) and interaction terms for CQ and time into the final model, which is shown in Equation (1).

$$
\begin{gathered}
R t_{i, t}=\alpha+\beta_{1} \text { AirPressure }_{i, t}+\beta_{2} \text { AirPressure }_{i, t-7}+\beta_{3} \text { Test }_{i, t}+\beta_{4} \text { dow } \\
+\beta_{5} \text { CQ }: \text { time }+\beta_{6} \text { time }+ \text { random } \mid \text { city }
\end{gathered}
$$

$R t_{i, t}$ is the time-varying $\mathrm{R}_{\mathrm{t}}$ of city (i) in time $(t) ; \alpha$ is the intercept; AirPressure $e_{i, t}$ and AirPressure $_{i, t-7}$ are the terms representing same-day air pressure and 7-day lagged air pressure, respectively; dow is a categorical variable indicating the day of the week; Test $t_{i, t}$ is the same-day RT-PCR test; CQ is a categorical term with 4 levels; time is a continuous term; CQ:time is the interaction term for CQ and time; city was assumed as a random effect. All analyses were carried out using R Statistical Programming Language [41].

\section{Results}

We observed statistically significant differences in the mean of incident cases, average temperature, dew point, relative humidity, visibility, RT-PCR tests and $\mathrm{R}_{t}$ among the cities, except for air pressure, as shown in Table 1 . The mean incident cases of Quezon city are comparatively higher than those of Manila and Cebu cities. Apart from the COVID-19 incidence, the time-varying $R_{t}$ 's among the cities are substantially different from each other, with Cebu city having a mean $R_{t}$ of 1.69 , which is greater than Manila (mean $R_{t}=1.20$ ) and Quezon city (mean $R_{t}=1.18$ ). The higher $R_{t}$ observed in Cebu is mirrored in its cumulative incidence (per 1000 population), in Table S1, at 11 confirmed cases per 1000 population. Further examination revealed that only air pressure, albeit weak, was positively correlated with $R_{t}$ as depicted in Figure 1. Statistically significant correlations ranging from weak to strong are shown in gradient colors; statistically not significant associations are depicted with a blank space.

Statistically significant associations are shown in gradient colors. Positive correlations are represented with blue gradient, whereas negative associations are shown in red gradient. The darker the colors, the higher the correlation coefficient. Not significant correlations are depicted with blank spaces.

GAM results revealed that same-day (unlagged) covariates of air pressure, RT-PCR tests and interaction terms of CQ and time showed statistically significant associations with $R_{t}$, as shown in Table 2. Same-day air pressure and RT-PCR tests were associated with an increase in $R_{t}$, whereas all CQ categories, except for the first category $(C Q=1)$, indicated a statistically significant decrease. Air temperature, dew point, relative humidity, windspeed and visibility, on the other hand, indicated statistically non-significant positive effect estimates. Further examination of the delayed association of the covariates, through single lag models, indicated a range of immediate and delayed effects of air pressure (Lags 0 to 8) and RT-PCR tests (Lags 0 to 7 ) on $R_{t}$, as shown in Figure 2. We, however, 
did not observe any significant delayed association with average temperature, dew point, relative humidity, windspeed, and visibility (Figure S5). Same-day RT-PCR tests were observed to be associated with a significant increase in $R_{t}$, which decays until Lag 5 and eventually approached the null association. Whereas, we observed a decay in the association between air pressure and $\mathrm{R}_{\mathrm{t}}$ from Lag 0 to Lag 4 , which increased until Lag 7 and gradually decreased towards zero thereafter. $R_{t}$ was highest when air pressure was at Lag 7.

Table 1. City-specific health outcome and exposure summary statistics.

\begin{tabular}{|c|c|c|c|c|}
\hline Variables ${ }^{1,2, * *}$ & Manila City & Quezon City & Cebu City & $p$-Value ${ }^{3}$ \\
\hline Daily COVID-19 cases & $101.89(122.50)$ & $144.75(182.43)$ & $63.37(67.99)$ & $<0.001$ \\
\hline Average temperature $\left({ }^{\circ} \mathrm{C}\right)$ & $30.24(1.01)$ & $29.13(1.40)$ & $29.02(0.99)$ & $<0.001$ \\
\hline Dew point $\left({ }^{\circ} \mathrm{C}\right)$ & $24.16(1.15)$ & $23.56(1.24)$ & $24.25(0.73)$ & $<0.001$ \\
\hline Relative Humidity (\%) & $69.59(7.62)$ & $72.14(10.48)$ & $76.15(5.70)$ & $<0.001$ \\
\hline Air pressure $(\mathrm{kPa})$ & $100.95(0.15)$ & $100.94(0.17)$ & $100.95(0.15)$ & 0.351 \\
\hline Visibility $(\mathrm{km})$ & $6.48(0.31)$ & $5.06(0.43)$ & $6.14(0.15)$ & $<0.001$ \\
\hline Windspeed (m/s) & $5.18(1.30)$ & $2.71(0.60)$ & $5.01(1.07)$ & $<0.001$ \\
\hline$R_{t}$ & $1.20(0.76)$ & $1.18(0.74)$ & $1.69(3.09)$ & 0.0273 \\
\hline RT-PCR tests (per 1000 population) ${ }^{4}$ & $10.21(6.74) *$ & $10.21(6.74) *$ & $1.04(0.73)$ & $<0.001$ \\
\hline
\end{tabular}

${ }^{1}$ Variables are presented in mean (standard deviation); $R_{t}=$ time-varying effective reproduction number. ${ }^{2}$ All variables are on a daily scale. ${ }^{3}$ One-way ANOVA test of statistically significant difference. ${ }^{4}$ RT-PCR tests are from the daily tests from unique individuals. For the sake of conciseness, RT-PCR tests were transformed from count to rate. ${ }^{*}$ Due to the difficulty in disentangling the referral health system in the National Capital Region which includes Manila and Quezon cities, we assumed similar trends for both. More details in the accompanying text of Supplementary Figure S4. ** Inclusive period: 3 April 2020 to 2 September 2020.

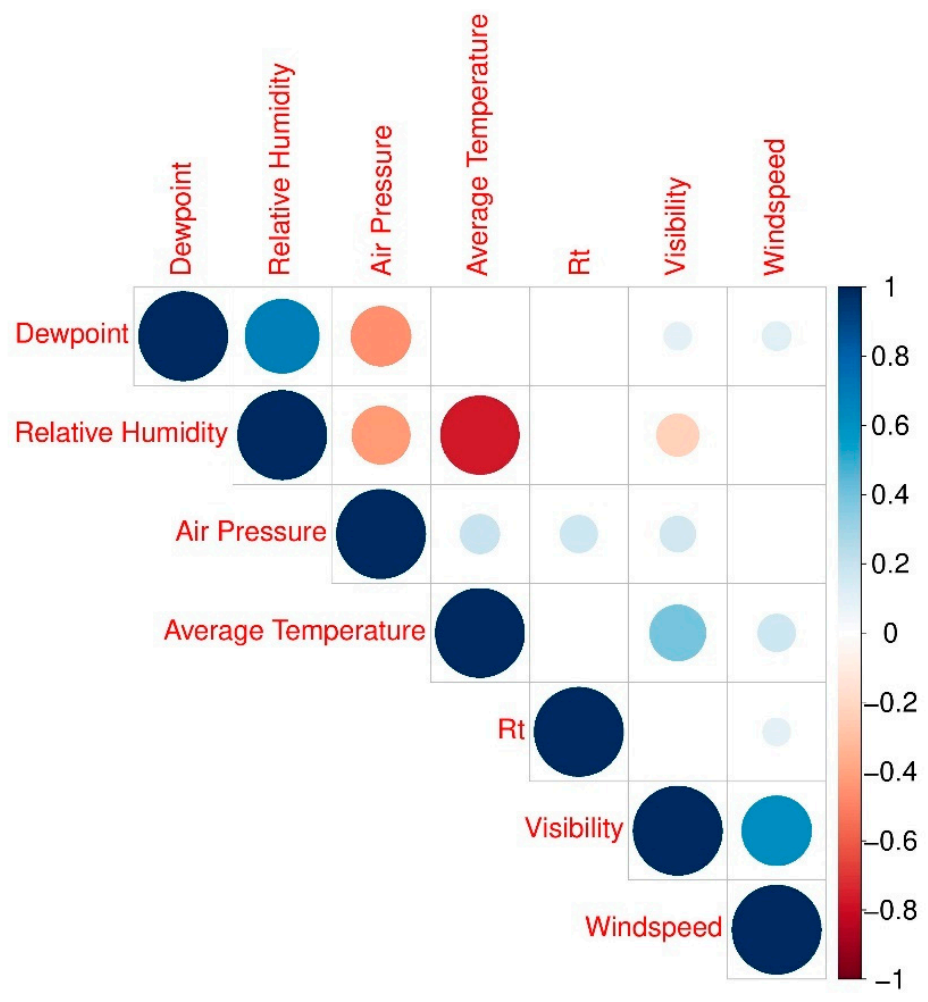

Figure 1. Matrix of correlation coefficients of exposure variables and $\mathrm{R}_{\mathrm{t}}$. 
Table 2. Association of same-day exposure variables and $\mathrm{R}_{\mathrm{t}}$.

\begin{tabular}{cccc}
\hline- & $\beta$ & SE & $p$-Value \\
\hline 1 Base model & - & - & - \\
+ Air Pressure & 1.95473 & 0.69273 & $0.00500 *$ \\
+Air temperature & 0.02125 & 0.07804 & 0.78600 \\
+Dew point & 0.09836 & 0.09914 & 0.32169 \\
+ Relative Humidity & 0.01002 & 0.01346 & 0.45692 \\
+Visibility & -0.02081 & 0.19820 & 0.91643 \\
+Windspeed & 0.10784 & 0.07467 & 0.14950 \\
+ RT-PCR tests & 0.08219 & 0.02551 & $0.00137^{*}$ \\
+CQ:Time & & & \\
CQ 1:Time & -0.00999 & 0.00774 & 0.19739 \\
CQ 2:Time & -0.00799 & 0.00226 & $0.00045^{*}$ \\
CQ 3:Time & -0.00617 & 0.00271 & $0.02324 *$ \\
CQ 4:Time & -0.01546 & 0.00458 & $0.00079 *$
\end{tabular}

The base model consists of the temporal control for time and day of the week. All succeeding models included the base model temporal adjustments. ${ }^{*}$ Asterisks indicate statistical significance at $p$-value $<0.05$. RT-PCR $=$ reverse transcriptase polymerase chain reaction; $C Q=$ community quarantine; $C Q$ :Time = interaction of $C Q$ with time; $\mathrm{CQ}=1$ (Modified General Community Quarantine); $\mathrm{CQ}=2$ (General Community Quarantine); $\mathrm{CQ}=3$ (Modified Enhanced Community Quarantine); $C Q=4$ (Enhanced Community Quarantine); $\beta=$ beta coefficient; $\mathrm{SE}=$ standard error

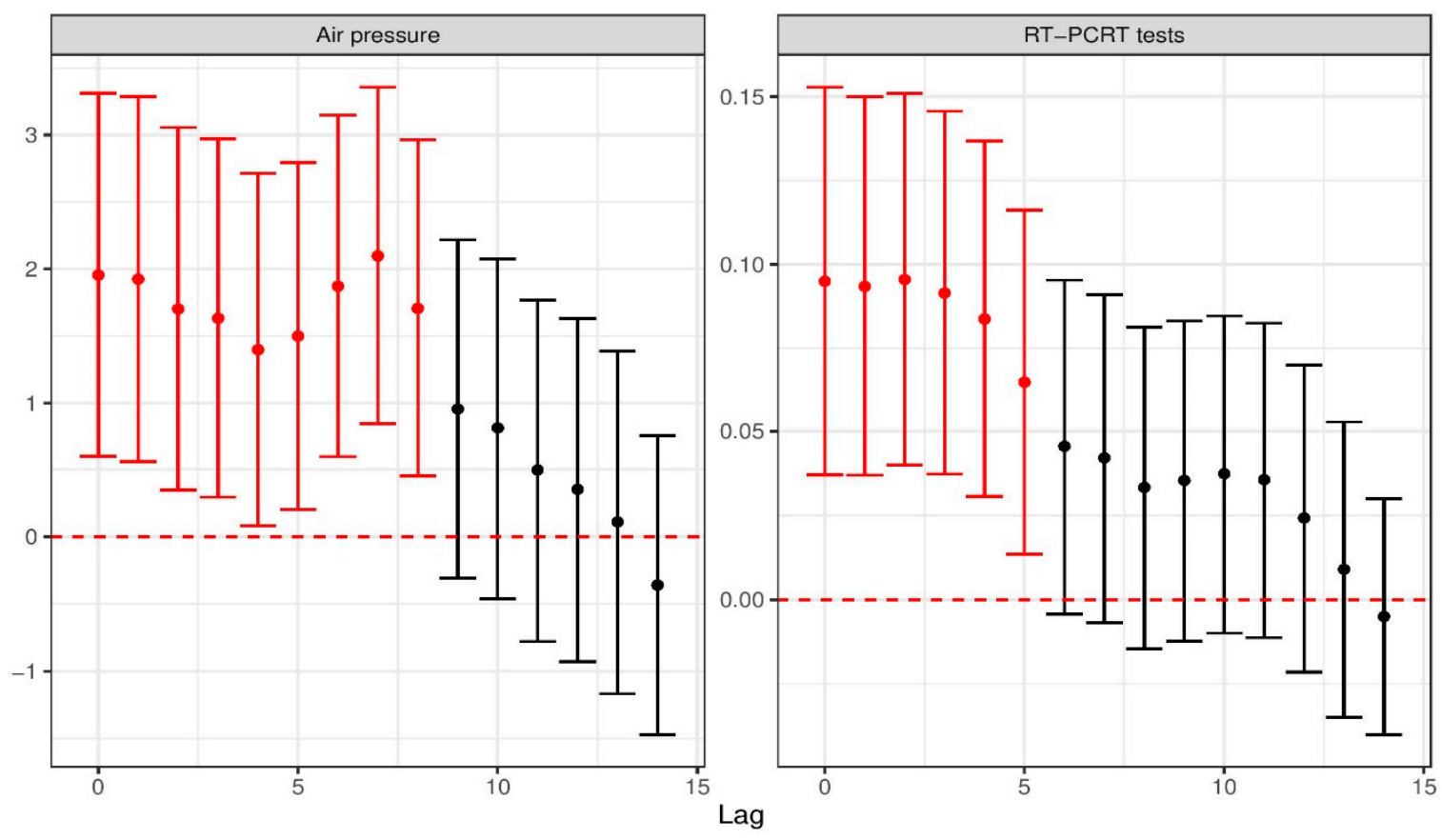

Figure 2. Lagged associations of air pressure and RT-PCR tests on $R_{t}$.

Statistically significant associations are shown in red, whereas null associations are in black. The red vertical dotted line represents the null association.

Covariates which showed statistically significant same-day and delayed association with $R_{t}$ were included in the initial full model. Utilizing a stepwise-regression via backward elimination, the final model shown in Table S3, retained same-day (Lag 0) and delayed (Lag 7) air pressure, same-day (Lag 0) RT-PCR tests and the interaction of CQ and time. $R_{t}$, while exhibiting a statistically positive association with air pressure, was observed to have greater magnitude $(\beta=2.59)$ of increase with same-day air pressure compared to the previous week's $(\beta=2.26)$, as shown in Table 3. Similar to air pressure, RT-PCR tests showed a positively significant association, albeit with lower magnitude $(\beta=0.14)$. On the other hand, all CQ categories indicated strong evidence of a statistically negative association with $R_{t}$, except for the first CQ category, which showed marginal statistical significance. 
Table 3. Summary results of the final model using stepwise regression.

\begin{tabular}{cccc}
\hline Covariate & $\boldsymbol{\beta}$ & SE & $p$-Value \\
\hline Air Pressure (Lag 0) & 2.59425 & 0.68426 & $<0.001$ \\
Air Pressure (Lag 7) & 2.25998 & 0.63500 & $<0.001$ \\
RT-PCR tests (Lag 0) & 0.14491 & 0.03068 & $<0.001$ \\
CQ:Time & & & \\
CQ 1:Time & -0.01496 & 0.00807 & 0.06366 \\
CQ 2:Time & -0.01671 & 0.00417 & $<0.001$ \\
CQ 3:Time & -0.01385 & 0.00486 & 0.00437 \\
CQ 4:Time & -0.02743 & 0.00616 & $<0.001$ \\
\hline
\end{tabular}

Note: Final model adjusted for temporal trends of time and day of the week. RT-PCR = reverse transcriptase polymerase chain reaction; $C Q=$ community quarantine; $C Q: T i m e=$ interaction of $C Q$ with time; $C Q=1$ (Modified General Community Quarantine); $\mathrm{CQ}=2$ (General Community Quarantine); $\mathrm{CQ}=3$ (Modified Enhanced Community Quarantine); $\mathrm{CQ}=4$ (Enhanced Community Quarantine); $\beta=$ beta coefficient; $\mathrm{SE}=$ standard error.

\section{Discussion}

In this study, we observed significant positive immediate and delayed effects of air pressure on the infectiousness of COVID-19 in the Philippines. Furthermore, we observed that detection and intervention-related covariates showed different directions in association with COVID-19 infectiousness. RT-PCR tests showed a positive increase, whereas community quarantines were found to be statistically associated with the decrease in COVID-19 infectiousness.

\subsection{Temperature, Relative Humidity, and Other Meteorological Variables and COVID-19 Infectiousnes}

Several studies have examined the association of meteorological variables with COVID19 , with indications of an association particularly with ambient temperature exposure [16,45]. In China, Qi et al. [16] observed that same-day ambient temperature was negatively associated (central estimate $=-3.61 ; 95 \%$ Confidence Interval (CI): -6.46 to -0.75 ) COVID19 incidence in Hubei, China, whereas Liu et al. [45] observed the delayed negative effects of temperature on the incidence among 17 cities in China. Tobias and Molina [46], on the other hand, noted a negative association between COVID-19 and same-day temperature in Spain. Contrary to these studies, our results indicated the lack of an association. Yao et al. [47] similarly observed that temperature is not associated with COVID-19 incidence in 224 Chinese cities. Apart from temperature, several studies have noted relative humidity to be associated with the infectiousness of COVID-19. Qi et al. [16] and Liu et al. [45] observed the negative association of relative humidity with COVID-19. Our results, however, indicated the lack of an association. Notwithstanding previous literatures which indicated that the increase in temperature and relative humidity would lead to a reduction in COVID-19 infectiousness [48,49], our results indicated otherwise. The differences between these results may have been due to location-specific characteristics, which include but are not limited to climate variability [50], transmission rates [51] and policy interventions [52].

\subsection{Air Pressure and COVID-19 Infectiousness}

Almost all meteorological variables exhibited the lack of a clear association with COVID-19 infectiousness, except for air pressure. In Table 3, air pressure on the same day and as well as the previous week's air pressure is linearly associated with the increase in COVID-19 infectiousness. This was initially observed in the positive correlation shown in Figure 1. Li et al. [25] observed that the high-risk window of the avian influenza (H5N1) viral infection corresponded with the air pressure interval of 980 to 1025 kilopascal $(\mathrm{kPa})$, whereas similar observations were shared by Guo et al. [53] who noted that the risk of influenza increases with rising atmospheric pressure. Bhaganagar and Bhimireddy [54] suggest that atmospheric stability with dry conditions may accelerate the viral spread through short-range droplet transmission. The authors noted that atmospheric stability regimes that result in low wind speeds, low level turbulence and cool moist ground 
conditions favor the transmission of the disease, with the possibility of virus spreading up to $30 \mathrm{~min}$ in the air, covering a 200-m radius at a time, moving $1-2 \mathrm{~km}$ from the original source [54]. While this may provide an insight into the dynamics of the immediate impact of air pressure on COVID-19 infectiousness, there is no clear mechanistic/physiological pathway explaining the delayed association. However, a study in Australia noted that COVID-19 can remain infectious for extended periods, with the virus persisting even beyond two weeks in contaminated surfaces, increasing the risk of fomite transmission [55]. While there is a possibility that air pressure, similar to humidity and temperature, may present both physical and chemical dynamics related to viral viability [56], this remains to be elucidated, thus warranting further studies.

\subsection{Short-Term Impact of Testing on COVID-19 Infectiousness}

Apart from air pressure, we observed that COVID-19-related detection and intervention measures were found to be associated with the time-varying infectiousness. An increase in same-day RT-PCR tests was associated with a positive increase in $R_{t}$, which gradually decayed until Lag 5 and approached the null association thereafter, as shown in Figure 2. Katul et al. [36] notes that high testing frequency would lead to an increase in confirmed cases, which subsequently translate to an increase in $R_{t}$ in the short run, particularly in the early phase of the pandemic. However, in the long run, increased testing, holding all other factors constant, should ideally decrease the COVID-19 transmission and thus decreasing $R_{\mathrm{t}}$ [57]. In a mathematical simulation, Grassly et al. [58] demonstrated that PCR testing was estimated to reduce SARS-CoV-2 transmission by $23 \%$ ( $95 \%$ uncertainty interval: $16-40 \%$ ) if carried out effectively. We ran a sensitivity analyses with maximum lag for 60 days (2 months) to visualize if indeed, in the long run, extended lags of RT-PCR tests would result in a decrease in the infectiousness; the results are shown in Figure S6. Here, we observed a significant decrease in $R_{t}$ around Lags 46 to 55 . Caution, however, should be exercised in the interpretation of intermediate lags since the covariate was lagged for 2 months out of the total of 5-month study period. A longer study period to examine longer lag effects would be suitable for subsequent examination of the association. Even so, current results provide hindsight to the relative importance of COVID-19 testing on infectiousness and should be adjusted accordingly. Non-adjustment of testing would eventually bias the estimates of the environmental exposures of interest. That being said, it is equally important to establish the validity, correctness and timeliness of testing so that it can improve the model, rather than introducing more uncertainty (due to improper and untimely testing).

\subsection{Community Measures and Its Effect on COVID-19 Infectiousnes}

CQ, on the other hand, was found to be associated with the decrease in COVID-19 infectiousness, which is similar to several studies assessing the impact of control measures on the progression of the pandemic [59-61]. The greatest decrease in $R_{t}$ was observed with the enhanced CQ $(=4)$, with the remaining CQ categories having nearly similar effects estimates, as shown in Table 3. In Europe, Flaxman et al. [62] noted that lockdowns, which are equivalent to enhanced CQ in the Philippines, substantially reduced $R_{t}$ by $81 \%$ (posterior credible intervals: $75-85 \%$ ). The lockdown in Wuhan, China, has similarly resulted in a decrease in COVID-19 transmission and progression, not just in the city, but also across China $[63,64]$. Lockdowns can structurally change the mobility of the population, thereby affecting disease transmission $[65,66]$. Compliance to these control measures resulted in discernable decrease in transmission; however, less stringent lockdowns may lead to a possible rebound of cases [66].

\subsection{Limitations}

Our study has several limitations. First, the data utilized reflected a portion of the ongoing pandemic. The data constraints may affect the robustness of the estimates given the limited period of modeling the association. Second, the ecological nature of the study can be 
affected by both city- and individual-level characteristics such as implementation measure, behavioral, spatial and sociodemographic factors. Further studies are needed to account for these factors with sufficient data. Third, the analyses framework presented, particularly on the covariate selection and modeling framework, may be further improved subject to the accumulated evidence and availability of data, in the context of the effect of meteorological variables on COVID-19 infectiousness. Fourth, the association of meteorological variables and COVID-19 may be beyond a linear theoretical framework [67], and thus non-linear examination is encouraged. In the current study, however, we did not find any discernable non-linear association (results not shown). Fifth, several urban dynamics, such as air pollution levels, were not controlled for in the model. Even so, several studies noted that air pollution levels during the COVID-19 pandemic have reduced [68]. Thus, we assumed that, during the pandemic, the effect of air pollution on infectiousness may not be that substantial. Sixth, the number of cities included as well as the number of covariates in the study may pose possible biases and residual confounding to the effects estimates. However, due to the limited data, we were not able to fully examine these limitations. A more comprehensive analysis utilizing a well-documented data source may provide insightful outcomes, which should be considered in future studies.

\subsection{Strengths}

Nevertheless, the study exemplifies several strengths. While the data are limited, this study utilized a 5-month-long daily COVID-19 dataset, which sets it apart from other studies utilizing a narrower observation window. Additionally, the study exhaustively accounted for the major timelines of community quarantine at the city level, shown in Figure S1 with summaries of community quarantine classification in Table S2. Adjustment of these community quarantine measures, and its timing are essential in comprehensively modeling the association. Likewise, the study adjusted for the daily number of RT-PCR tests. The increasing number of tests may induce bias particularly on its impact on the number of daily incidences and subsequent estimation of $R_{t}$. To the best of our knowledge, this is the first study which adjusted for the number of tests administered.

\section{Conclusions}

Same-day and the prior week's air pressure were found to be positively associated with COVID-19 infectiousness. COVID-19-related detection and intervention measures resulted to different directions in association with COVID-19 infectiousness. Same-day RT-PCR tests resulted in a positive increase, while community quarantines were found to be statistically associated with a decrease in infectiousness. The determination of the association of air pressure on infectiousness, aside from the testing frequency and community quarantine measures, may aide the current health systems in controlling COVID-19 infectiousness via a more integrated approach of an early warning platform.

Supplementary Materials: The following are available online at https:/ /www.mdpi.com/article/10 $.3390 /$ atmos12040513/s1, Figure S1. Timeline of community quarantine measures in the three major cities of the Philippines; Figure S2. Geographical locations of the monitoring stations per city across the country (left) alongside zoomed-in locations for Manila and Quezon cities (right, upper) and Cebu city (right, lower); Figure S3. Time-varying $R_{t}$ and daily number of COVID-19 cases in Cebu city (upper panel), Manila city (middle panel) and C) Quezon city (lower panel); Figure S4. Geographical location and administrative boundaries of the National Capital Region (left) and Cebu Island (right); Figure S5. Lag-specific association of $\mathrm{R}_{\mathrm{t}}$ and average temperature (leftmost, upper panel), dewpoint (middle, upper panel), relative humidity (rightmost, upper panel), visibility (leftmost, lower panel) and windspeed (middle, lower panel); Figure S6. Extended lagged association of RT-PCR tests and $\mathrm{R}_{\mathrm{t}}$. Table S1. Characteristics of Top 5 cities in the Philippines with the most COVID-19 cases from 3 April 2020 to 2 September 2020; Table S2. Definition of community quarantine classifications; Table S3. Stepwise regression via backward elimination results. 
Author Contributions: X.S. was involved in the conceptualization of the study, data gathering, analysis and interpretation of results. C.F.S.N. and L.M. were involved in the interpretation of the results. All authors have read and agreed to the published version of the manuscript.

Funding: This research received no external funding.

Institutional Review Board Statement: Not applicable.

Informed Consent Statement: Not applicable.

Data Availability Statement: Daily COVID-19 data in the Philippines can be accessed through the Philippine COVID-19 tracker (https://doh.gov.ph/covid19tracker-accessed on 10 October 2020), whereas the relevant meteorological variables can be accessed via the NOAA website (https:/ / www.ncdc.noaa.gov/—accessed on 10 October 2020).

Conflicts of Interest: The authors declare no conflict of interest.

\section{References}

1. Zhu, N.; Zhang, D.; Wang, W.; Li, X.; Yang, B.; Song, J.; Zhao, X.; Huang, B.; Shi, W.; Lu, R.; et al. A Novel Coronavirus from Patients with Pneumonia in China, 2019. N. Engl. J. Med. 2020, 382, 727-733. [CrossRef]

2. WHO. WHO Director-General's Opening Remarks at the Mission Briefing on COVID-19. Available online: https://www.who. $\mathrm{int} / \mathrm{dg} /$ speeches/detail/who-director-general-s-opening-remarks-at-the-mission-briefing-on-covid-19 (accessed on $12 \mathrm{March}$ 2020).

3. Wang, D.; Hu, B.; Hu, C.; Zhu, F.; Liu, X.; Zhang, J.; Wang, B.; Xiang, H.; Cheng, Z.; Xiong, Y.; et al. Clinical Characteristics of 138 Hospitalized Patients With 2019 Novel Coronavirus-Infected Pneumonia in Wuhan, China. JAMA 2020, 323, $1061-1069$. [CrossRef]

4. Liu, J.; Liao, X.; Qian, S.; Yuan, J.; Wang, F.; Liu, Y.; Wang, Z.; Wang, F.-S.; Liu, L.; Zhang, Z. Community Transmission of Severe Acute Respiratory Syndrome Coronavirus 2, Shenzhen, China, 2020. Emerg. Infect. Dis. 2020, 26. [CrossRef] [PubMed]

5. Anderson, R.M.; Heesterbeek, H.; Klinkenberg, D.; Hollingsworth, T.D. How will Country-Based Mitigation Measures Influence the Course of the COVID-19 Epidemic? Lancet 2020, 395, 931-934. [CrossRef]

6. CSIS Southeast Asia Covid-19 Tracker. Available online: https://www.csis.org/programs/southeast-asia-program/southeastasia-covid-19-tracker-0 (accessed on 17 April 2021).

7. DOH. COVID-19 tracker: Philippines. Available online: https://ncovtracker.doh.gov.ph/ (accessed on 10 October 2020).

8. Proclamation no. 922: Declaring a State of Public Health Emergency throughout the Philippines. Available online: https: //www.officialgazette.gov.ph/downloads/2020/03mar/20200308-PROC-922-RRD.pdf (accessed on 10 October 2020).

9. IATF. Recommendations for the Management of the Coronavirus Disease 2019 (COVID-19) Situation. Available online: https: // doh.gov.ph/COVID-19/IATF-Resolutions (accessed on 10 October 2020).

10. IATF. Omnibus Guidelines on the Implementation of Community Quarantine in the Philippines. Available online: https: // doh.gov.ph/COVID-19/IATF-Resolutions (accessed on 10 October 2020).

11. IATF. COVID-19 Inter-Agency Task Force for the Management of Emerging Infectious Diseases Resolutions. Available online: https:/ / doh.gov.ph/COVID-19/IATF-Resolutions (accessed on 20 October 2020).

12. Li, Q.; Guan, X.; Wu, P.; Wang, X.; Zhou, L.; Tong, Y.; Ren, R.; Leung, K.S.M.; Lau, E.H.Y.; Wong, J.Y.; et al. Early Transmission Dynamics in Wuhan, China, of Novel Coronavirus-Infected Pneumonia. N. Engl. J. Med. 2020, 382, 1199-1207. [CrossRef] [PubMed]

13. Liu, Y.; Yan, L.-M.; Wan, L.; Xiang, T.-X.; Le, A.; Liu, J.-M.; Peiris, M.; Poon, L.L.M.; Zhang, W. Viral Dynamics in Mild and Severe Cases of COVID-19. Lancet Infect. Dis. 2020, 20, 656-657. [CrossRef]

14. Wang, L.; Gao, Y.-H.; Lou, L.-L.; Zhang, G.-J. The Clinical Dynamics of 18 Cases of COVID-19 Outside of Wuhan, China. Eur. Respir. J. 2020, 55, 2000398. [CrossRef] [PubMed]

15. Zhang, J.; Litvinova, M.; Wang, W.; Wang, Y.; Deng, X.; Chen, X.; Li, M.; Zheng, W.; Yi, L.; Chen, X.; et al. Evolving Epidemiology and Transmission Dynamics of Coronavirus Disease 2019 Outside Hubei Province, China: A Descriptive and Modelling Study. Lancet Infect. Dis. 2020, 20, 793-802. [CrossRef]

16. Qi, H.; Xiao, S.; Shi, R.; Ward, M.P.; Chen, Y.; Tu, W.; Su, Q.; Wang, W.; Wang, X.; Zhang, Z. COVID-19 Transmission in Mainland China is Associated with Temperature and Humidity: A Time-Series Analysis. Sci. Total Environ. 2020, 728, 138778. [CrossRef]

17. Şahin, M. Impact of Weather on COVID-19 Pandemic in TURKEY. Sci. Total Environ. 2020, 728, 138810. [CrossRef] [PubMed]

18. Fattorini, D.; Regoli, F. Role of the Chronic Air Pollution Levels in the Covid-19 Outbreak Risk in Italy. Environ. Pollut. 2020, 264, 114732. [CrossRef]

19. Bashir, M.F.; Ma, B.; Bilal; Komal, B.; Bashir, M.A.; Tan, D.; Bashir, M. Correlation between Climate Indicators and COVID-19 Pandemic in New York, USA. Sci. Total Environ. 2020, 728, 138835. [CrossRef] [PubMed]

20. Tosepu, R.; Gunawan, J.; Effendy, D.S.; Ahmad, L.O.A.I.; Lestari, H.; Bahar, H.; Asfian, P. Correlation between Weather and Covid-19 Pandemic in Jakarta, Indonesia. Sci. Total Environ. 2020, 725, 138436. [CrossRef] 
21. McClymont, H.; Hu, W. Weather Variability and COVID-19 Transmission: A Review of Recent Research. Int. J. Environ. Res. Public Health 2021, 18, 396. [CrossRef]

22. Bukhari, Q.; Massaro, J.M.; D'Agostino, S.R.B.; Khan, S. Effects of Weather on Coronavirus Pandemic. Int. J. Environ. Res. Public Health 2020, 17, 5399. [CrossRef] [PubMed]

23. Kodera, S.; Rashed, E.A.; Hirata, A. Correlation between COVID-19 Morbidity and Mortality Rates in Japan and Local Population Density, Temperature, and Absolute Humidity. Int. J. Environ. Res. Public Health 2020, 17, 5477. [CrossRef] [PubMed]

24. Park, J.-E.; Son, W.-S.; Ryu, Y.; Choi, S.B.; Kwon, O.; Ahn, I. Effects of Temperature, Humidity, and Diurnal Temperature Range on Influenza Incidence in a Temperate Region. Influ. Respir. Viruses 2020, 14, 11-18. [CrossRef]

25. Li, J.; Rao, Y.; Sun, Q.; Wu, X.; Jin, J.; Bi, Y.; Chen, J.; Lei, F.; Liu, Q.; Duan, Z.; et al. Identification of Climate Factors Related to Human Infection with Avian Influenza A H7N9 and H5N1 Viruses in China. Sci. Rep. 2015, 5, 18094. [CrossRef]

26. Gardner, E.G.; Kelton, D.; Poljak, Z.; Van Kerkhove, M.; Von Dobschuetz, S.; Greer, A.L. A Case-Crossover Analysis of the Impact of Weather on Primary Cases of Middle East Respiratory Syndrome. BMC Infect. Dis. 2019, 19, 1-10. [CrossRef] [PubMed]

27. Cori, A.; Ferguson, N.M.; Fraser, C.; Cauchemez, S. A New Framework and Software to Estimate Time-Varying Reproduction Numbers During Epidemics. Am. J. Epidemiol. 2013, 178, 1505-1512. [CrossRef]

28. Al-Rousan, N.; Al-Najjar, H. The Correlation between the Spread of COVID-19 Infections and Weather Variables in 30 Chinese Provinces and the Impact of Chinese Government Mitigation Plans. Eur. Rev. Med. Pharmacol. Sci. 2020, 24, 4565-4571. [PubMed]

29. Chen, Y. COVID-19 Pandemic Imperils Weather Forecast. Geophys. Res. Lett. 2020, 47, e2020GL088613. [CrossRef]

30. Gupta, S.; Raghuwanshi, G.S.; Chanda, A. Effect of Weather on COVID-19 Spread in the US: A Prediction Model for India in 2020. Sci. Total Environ. 2020, 728, 138860. [CrossRef] [PubMed]

31. Ogaugwu, C.; Mogaji, H.; Ogaugwu, E.; Nebo, U.; Okoh, H.; Agbo, S.; Agbon, A. Effect of Weather on COVID-19 Transmission and Mortality in Lagos, Nigeria. Scientifica Cairo 2020, 2020, 1-6. [CrossRef]

32. Rosario, D.K.A.; Mutz, Y.S.; Bernardes, P.C.; Conte-Junior, C.A. Relationship between COVID-19 and Weather: Case Study in a Tropical Country. Int. J. Hyg. Environ. Health 2020, 229, 113587. [CrossRef]

33. Viglione, G. How COVID-19 Could Ruin Weather Forecasts and Climate Records. Nat. Cell Biol. 2020, 580, 440-441. [CrossRef]

34. Seposo, X.T.; Dang, T.N.; Honda, Y. Effect Modification in the Temperature Extremes by Mortality Subgroups among the Tropical Cities of the Philippines. Glob. Health Action 2016, 9, 31500. [CrossRef] [PubMed]

35. Villafuerte, M.Q.; Macadam, I.; Daron, J.; Katzfey, J.; Cinco, T.A.; Ares, E.D.; Jones, R.G. Projected Changes in Rainfall and Temperature over the Philippines from Multiple Dynamical Downscaling Models. Int. J. Clim. 2020, 40, 1784-1804. [CrossRef]

36. Katul, G.G.; Mrad, A.; Bonetti, S.; Manoli, G.; Parolari, A.J. Global Convergence of COVID-19 Basic Reproduction Number and Estimation from Early-Time SIR Dynamics. PLoS ONE 2020, 15, e0239800. [CrossRef] [PubMed]

37. Pan, A.; Liu, L.; Wang, C.; Guo, H.; Hao, X.; Wang, Q.; Huang, J.; He, N.; Yu, H.; Lin, X.; et al. Association of Public Health Interventions With the Epidemiology of the COVID-19 Outbreak in Wuhan, China. JAMA 2020, 323, 1915. [CrossRef]

38. NOAA-NCDC. Global Climate Station Summaries. Available online: https://www7.ncdc.noaa.gov/CDO/cdoselect.cmd? datasetabbv=SUMMARIES (accessed on 10 October 2020).

39. Towers, S.; Patterson-Lomba, O.; Castillo-Chavez, C. Temporal Variations in the Effective Reproduction Number of the 2014 West Africa Ebola Outbreak. PLoS Curr. 2014, 6, 6. [CrossRef]

40. Cori, A. EpiEstim: Estimate Time Varying Reproduction Numbers from Epidemic Curves. Available online: https://rdrr.io/cran/ EpiEstim/ (accessed on 10 October 2020).

41. Team, R.C. A Language and Environment for Statistical Computing; R Foundation for Statistical Computing. Available online: https:/ / www.gbif.org/tool/81287/r-a-language-and-environment-for-statistical-computing (accessed on 10 October 2020).

42. Lauer, S.A.; Grantz, K.H.; Bi, Q.; Jones, F.K.; Zheng, Q.; Meredith, H.R.; Azman, A.S.; Reich, N.G.; Lessler, J. The Incubation Period of Coronavirus Disease 2019 (COVID-19) From Publicly Reported Confirmed Cases: Estimation and Application. Ann. Intern. Med. 2020, 172, 577-582. [CrossRef]

43. Qin, J.; You, C.; Lin, Q.; Hu, T.; Yu, S.; Zhou, X.-H. Estimation of Incubation Period Distribution of COVID-19 Using Disease Onset forward Time: A Novel Cross-Sectional and forward Follow-Up Study. Sci. Adv. 2020, 6, eabc1202. [CrossRef] [PubMed]

44. Smith, G. Step Away from Stepwise. J. Big Data 2018, 5, 32. [CrossRef]

45. Liu, J.; Zhou, J.; Yao, J.; Zhang, X.; Li, L.; Xu, X.; He, X.; Wang, B.; Fu, S.; Niu, T.; et al. Impact of Meteorological Factors on the COVID-19 Transmission: A Multi-City Study in China. Sci. Total Environ. 2020, 726, 138513. [CrossRef] [PubMed]

46. Tobías, A.; Molina, T. Is Temperature Reducing the Transmission of COVID-19? Environ. Res. 2020, 186, 109553. [CrossRef] [PubMed]

47. Yao, Y.; Pan, J.; Liu, Z.; Meng, X.; Wang, W.; Kan, H.; Wang, W. No Association of COVID-19 Transmission with Temperature or UV Radiation in Chinese Cities. Eur. Respir. J. 2020, 55, 2000517. [CrossRef] [PubMed]

48. Wang, J.; Tang, K.; Feng, K.; Lin, X.; Lv, W.; Chen, K.; Wang, F. Impact of Temperature and Relative Humidity on the Transmission of COVID-19: A Modelling Study in China and the United States. BMJ Open 2021, 11, e043863. [CrossRef]

49. Haque, S.E.; Rahman, M. Association between Temperature, Humidity, and COVID-19 Outbreaks in Bangladesh. Environ. Sci. Policy 2020, 114, 253-255. [CrossRef]

50. Sajadi, M.M.; Habibzadeh, P.; Vintzileos, A.; Shokouhi, S.; Miralles-Wilhelm, F.; Amoroso, A. Temperature, Humidity, and Latitude Analysis to Estimate Potential Spread and Seasonality of Coronavirus Disease 2019 (COVID-19). JAMA Netw. Open 2020, 3, e2011834. [CrossRef] 
51. Notari, A. Temperature Dependence of COVID-19 Transmission. Sci. Total Environ. 2021, 763, 144390. [CrossRef] [PubMed]

52. Brauner, J.M.; Mindermann, S.; Sharma, M.; Johnston, D.; Salvatier, J.; Gavenčiak, T.; Stephenson, A.B.; Leech, G.; Altman, G.; Mikulik, V.; et al. Inferring the Effectiveness of Government Interventions against COVID-19. Science 2021, 371, eabd9338. [CrossRef] [PubMed]

53. Guo, Q.; Dong, Z.; Zeng, W.; Ma, W.; Zhao, D.; Sun, X.; Gong, S.; Xiao, J.; Li, T.; Hu, W. The Effects of Meteorological Factors on Influenza among Children in Guangzhou, China. Influ. Respir. Viruses 2018, 13, 166-175. [CrossRef]

54. Bhaganagar, K.; Bhimireddy, S. Local Atmospheric Factors that Enhance Air-Borne Dispersion of Coronavirus-High-Fidelity Numerical Simulation of COVID19 Case Study in Real-Time. Environ. Res. 2020, 191, 110170. [CrossRef]

55. Riddell, S.; Goldie, S.; Hill, A.; Eagles, D.; Drew, T.W. The Effect of Temperature on Persistence of SARS-CoV-2 on Common Surfaces. Virol. J. 2020, 17, 145. [CrossRef]

56. Marr, L.C.; Tang, J.W.; Van Mullekom, J.; Lakdawala, S.S. Mechanistic Insights into the Effect of Humidity on Airborne Influenza Virus Survival, Transmission and Incidence. J. R. Soc. Interface 2019, 16, 20180298. [CrossRef]

57. Hellewell, J.; Abbott, S.; Gimma, A.; Bosse, N.I.; Jarvis, C.I.; Russell, T.W.; Munday, J.D.; Kucharski, A.J.; Edmunds, W.J.; Sun, F. Feasibility of Controlling COVID-19 Outbreaks by Isolation of Cases and Contacts. Lancet Glob. Health 2020, 8, e488-e496. [CrossRef]

58. Grassly, N.C.; Pons-Salort, M.; Parker, E.P.K.; White, P.J.; Ferguson, N.M.; Ainslie, K.; Baguelin, M.; Bhatt, S.; Boonyasiri, A.; Brazeau, N.; et al. Comparison of Molecular Testing Strategies for COVID-19 Control: A Mathematical Modelling Study. Lancet Infect. Dis. 2020, 20, 1381-1389. [CrossRef]

59. Liu, P.-Y.; He, S.; Rong, L.-B.; Tang, S.-Y. The Effect of Control Measures on COVID-19 Transmission in Italy: Comparison with Guangdong Province in China. Infect. Dis. Poverty 2020, 9, 1-13. [CrossRef]

60. Wu, D.; Lu, J.; Liu, Y.; Zhang, Z.; Luo, L. Positive Effects of COVID-19 Control Measures on Influenza Prevention. Int. J. Infect. Dis. 2020, 95, 345-346. [CrossRef]

61. Kraemer, M.U.G.; Yang, C.-H.; Gutierrez, B.; Wu, C.-H.; Klein, B.; Pigott, D.M.; Du Plessis, L.; Faria, N.R.; Li, R.; Hanage, W.P.; et al. The Effect of Human Mobility and Control Measures on the COVID-19 Epidemic in China. Science 2020, 368, 493-497. [CrossRef]

62. Flaxman, S.; Mishra, S.; Gandy, A.; Unwin, H.J.T.; Mellan, T.A.; Coupland, H.; Whittaker, C.; Zhu, H.; Berah, T.; Eaton, J.W.; et al. Estimating the Effects of Non-Pharmaceutical Interventions on COVID-19 in Europe. Nature 2020, 584, 257-261. [CrossRef]

63. Lau, H.; Khosrawipour, V.; Kocbach, P.; Mikolajczyk, A.; Schubert, J.; Bania, J.; Khosrawipour, T. The Positive Impact of Lockdown in Wuhan on Containing the COVID-19 Outbreak in China. J. Travel Med. 2020, 27, 3. [CrossRef]

64. Chinazzi, M.; Davis, J.T.; Ajelli, M.; Gioannini, C.; Litvinova, M.; Merler, S.; Piontti, A.P.Y.; Mu, K.; Rossi, L.; Sun, K.; et al. The Effect of Travel Restrictions on the Spread of the 2019 Novel Coronavirus (COVID-19) Outbreak. Science 2020, 368, 395-400. [CrossRef]

65. Schlosser, F.; Maier, B.F.; Jack, O.; Hinrichs, D.; Zachariae, A.; Brockmann, D. COVID-19 Lockdown Induces Disease-Mitigating Structural Changes in Mobility Networks. Proc. Natl. Acad. Sci. USA 2020, 117, 32883-32890. [CrossRef]

66. Vinceti, M.; Filippini, T.; Rothman, K.J.; Ferrari, F.; Goffi, A.; Maffeis, G.; Orsini, N. Lockdown Timing and Efficacy in Controlling COVID-19 using Mobile Phone Tracking. E Clin. Med. 2020, 25, 100457. [CrossRef]

67. Ran, J.; Zhao, S.; Han, L.; Liao, G.; Wang, K.; Wang, M.H.; He, D. A Re-Analysis in Exploring the Association between Temperature and COVID-19 Transmissibility: An Ecological Study with 154 Chinese Cities. Eur. Respir. J. 2020, 56, 2001253. [CrossRef] [PubMed]

68. Venter, Z.S.; Aunan, K.; Chowdhury, S.; Lelieveld, J. COVID-19 Lockdowns Cause Global Air Pollution Declines. Proc. Natl. Acad. Sci. USA 2020, 117, 18984-18990. [CrossRef] [PubMed] 